\title{
Active Disassembly for the End-of-Life Treatment of Flat Screen Televisions: Challenges and Opportunities
}

\author{
Jef R. Peeters $^{1}$, Paul Vanegas ${ }^{1,2}$, Wim Dewulf ${ }^{1,3}$, Joost R. Duflou ${ }^{1}$ \\ ${ }^{1}$ Department of Mechanical Engineering, Katholieke Universiteit Leuven, Belgium \\ ${ }^{2}$ University of Cuenca, Ecuador \\ ${ }^{3}$ Group T-International University College Leuven, K.U.Leuven Association, Belgium
}

\begin{abstract}
The principle of Active Disassembly (AD), in which innovative reversible fasteners can be simultaneously activated by an external trigger signal, enables a promising End-of-Life (EoL) treatment for electric and electronic products. Therefore, the economic and environmental constraints for implementing $\mathrm{AD}$ are discussed, as well as the information requirements for $\mathrm{AD}$. Furthermore, the potential benefits of properly implementing active fasteners in a Liquid Cristal Display (LCD) and a Plasma Display Panel television are presented based on a case study.
\end{abstract}

\section{Keywords: Active Disassembly, Flat Screen Televisions, Recycling, WEEE}

\section{INTRODUCTION}

There are three key motives for manufacturing and recycling companies to improve the end-of-life (EoL) treatment of Waste Electric and Electronic Equipment (WEEE). Firstly, customer environmental awareness is creating opportunities for "green marketing". According to Loannou et al., market trends and brand image reputation are two of the most dominant drivers for sustainable product design and manufacturing [1]. Accordingly, manufacturing companies can gain competitive advantage by incorporating Ecodesign in their product development. Secondly, the development of alternative EoL treatment strategies for WEEE is required to reduce the involved processing costs. The currently adopted EoL treatment strategies for WEEE are often characterized by a low to negative profitability [2]. According to Huisman et al., the main reasons for this low return are the high collection, transportation and treatment costs which cannot be covered by the revenues from the recovered components and materials [2]. Finally, the third key motive to improve the EoL treatment of WEEE are the European WEEE directive [3] and the upcoming recast of this directive [4]. The quotas of this recast will range from 50 to $70 \%$ with respect to recycling and a recovery rate of 70 to $80 \%$ depending on the product category is expected [4]. According to the current WEEE directive recycling means the reprocessing of a waste material for the original or other purposes, and recovery means the use of combustible waste as a means of generating energy through direct incineration [3], which currently is a common treatment for plastics. Furthermore, the European directives do not only affect recyclers but also manufacturers, since they increasingly require manufacturers to take full responsibility for the EoL treatment of their products.
The conventional EoL treatment strategies for electronic products, which are based on product shredding or smashing, only permit to recycle a limited amount of precious metals and plastics. Due to the considerable environmental impact when not reclaimed and the high economic value of these materials, improvements in the conventional EoL treatment of WEEE are required. Furthermore, some categories of electronic products contain a considerable amount of plastics, such as Liquid Cristal Display (LCD) flat screen televisions (FTVs) which contain about $30 \%$ plastics on a mass basis. For these product categories, it is crucial to develop EoL treatment strategies which include recycling of plastics to achieve the recycling rates of the upcoming recast of the WEEE directive and to recycle precious metals to lower the environmental impact of the EoL treatment $[5,6]$.

\section{ALTERNATIVE EOL STRATEGIES}

Different strategies to improve the EoL treatment of electrical and electronic equipment have been studied in prior research, such as:

- Manual disassembly strategy, for which the treatment cost is mainly related to the amount of time required to disassemble a product and the labor wages. Due to high labor costs in Europe, manual disassembly of WEEE is under the current circumstances generally characterized by a low to negative profitability [7].

- Automated disassembly, for which prior research has proven the technical feasibility of fully automating a non-destructive disassembly process for, among others, , personal computers [8] and mobile phones [9]. However, automating the disassembly process in an EoL treatment is currently limited by the variation of returned products, which requires a great capacity of recognition and intelligence $[10,11]$. 
- Advanced post-shredder separation strategy, for which different technologies have recently been developed to separate shredder residue based on (optical) material properties. However, prior projects demonstrate that the main challenges for implementing such a strategy are the high investment costs and the low separation efficiency of optical separation processes for WEEE $[12,13]$.

- Design For Disassembly (DFD), for which many efforts have been made in prior research, since the efficiency of disassembly operations can be significantly influenced by an optimization of the product structure [14]. However, the time to localize and identify connectors covers approximately $30 \%$ of the total disassembly time [15]. Furthermore, prior studies have shown that the economic feasibility of disassembly can only be guaranteed if the disassembly time and cost are reduced by at least $75 \%$ for electronic products [16]. Therefore, DFD strategies which require a localization and identification step have only a limited potential to make systematic disassembly a preferred EoL treatment [17].

To accomplish a decrease in disassembly time of more than $75 \%$, the development of fasteners with a lower technical disassembly complexity is required. Within prior research fasteners with an Active Disassembly (AD) functionality have been proposed [7, 18]. Active fasteners are connections for which a specific external trigger or a combination of triggers can initiate a simultaneous (oneto-many) unfastening process. Since AD allows simultaneously releasing fasteners within different products, $\mathrm{AD}$ is assumed to allow a productivity increase by a factor 5 to 10 , and to reduce the disassembly costs with up to $70 \%$ [16]. Therefore, active disassembly, when properly implemented, has the potential to shift an EoL treatment with systematic disassembly from a cost factor to a profit generating activity $[15,17]$.

\section{ACTIVE DISASSEMBLY}

\subsection{Trends to consider for Active Disassembly}

When developing components for future electronic products, different trends in the evolution of these products have to be taken into account. TRIZ, a problemsolving, analysis and forecasting tool derived from the study of patterns of inventions in the global patent literature, contains different interesting trends which can be related to the evolution of fasteners and electronic products, such as [19]:

- Smart materials: from passive to fully adaptive fasteners, e.g. made out of shape memory materials. The most advanced research on active disassembly yet is based on materials which are able to return to an initial shape when heated above the trigger temperature [20-25].

- Object segmentation: from monolithic solid fasteners to a segmented solid up to a vacuum to hold an assembly together. Some examples of AD fasteners which are in line with this trend are: Velcro made of shape memory materials $[18,26]$ and the use of a vacuum instead of glue to assemble photovoltaic cells [27].

- Evolution macro to nano scale: miniaturization is a clear trend for electronic products and accordingly for the fasteners used in these products. Unfortunately, this impedes the implementation of some prior developed active fasteners in today's products. For example fasteners which make use of the extension of water when freezing or pneumatic expansion are difficult to implement in the current generation of FTVs, which continuously decrease in thickness [28, 29] .

\subsection{Ecologic and economic constraints}

To allow an industrial implementation of $\mathrm{AD}$ both ecological and economic constrains should be considered. Therefore, it is important to select a working principle for $\mathrm{AD}$ which requires only a limited amount of trigger energy. For that reason, working principles for AD, such as the chemical reaction proposed by Suga et al. [30, 31], where a hydrogen storage alloy is pulverized in a hydrogen atmosphere under a pressure of $4 \mathrm{MPa}$ and a temperature of $100{ }^{\circ} \mathrm{C}$, are less interesting for an industrial implementation. Also, thermally triggered active fasteners require a substantial amount of energy for heating up or cooling down electronic products above or below the broad temperature range of the use phase. Furthermore, the amount of scarce materials in active fasteners should be limited or a significant percentage of the connectors should be recycled to reduce both the ecological impact and cost of implementing an AD strategy.

Besides these constraints, one of the main challenges for implementing $\mathrm{AD}$ in an industrial setting is the required investment for the application of releasable joints. The integration of these joints in the product design at the outset of a product's lifecycle represents only minor benefits for the producer, for e.g. during maintenance under warranty obligations. The main returns of this investment are only obtained at the end of the lifecycle, when the product is typically no longer owned by the producer. For this reason, a holistic life cycle approach is desired for most electronic consumer products, in which all different actors in the lifecycle are involved. Nevertheless, producers or companies who offer their products in a Product Service System (PSS) can significantly benefit from an EoL strategy with AD, since these companies may also be responsible for the EoL treatment of their products.

\section{INFORMATION REQUIREMENTS}

Nowadays, information associated with products is gradually lost after the point of sale, which is one of the major obstacles for efficient recovery of value from EoL products [32]. As long as no standard active fasteners are commonly implemented, an efficient identification of products with active fasteners and information about the corresponding trigger are essential. Furthermore, 
information about the product composition and structure is required to allow a correct sorting for further treatment of components once a product is disassembled regardless of the adopted EoL treatment strategy.

The desirable properties of product information can be described by three dimensions: the level of detail of the product information, the ability of product identification and the product information location. Firstly, the required level of detail of the product information depends on the envisaged EoL treatment, for e.g. with manual or automated sorting. However, potential improvements in the current EoL treatment strategies need to be taken into account. Therefore, highly detailed product information should be accessible for the envisaged EoL treatments. Secondly, the product identification can be facilitated by implementing product identification technologies in products. For example, bar code labels, which are commonly placed on FTVs for logistic reasons, can sometimes still be used to identify the product model at the EoL of the product. The product model can then be used to look up detailed product information. However, often more than one barcode is attached to every product and barcode labels are sometimes damaged during the use phase [32]. For these reasons, the reliability and efficiency of the identification can be improved by applying modern identification technologies, such as Radio Frequency Identification (RFID), which allows a fast and remote identification of products using radio waves [32]. Finally, if product identification is possible, it does not necessarily means that the information needs to be located at the product. Two extreme scenarios can be identified here: information access through a data network or information integrated in the product [33]. A system which enables to integrate fundamental information to a product and access more detailed product information through a data network seems most appropriate for this application. In this way manufacturers will be able to better protect their Intellectual Property (IP) and can choose when to share which product information, e.g. to only share detailed information when products reach their EoL. Furthermore, such a system can support a business model in which the product manufacturer is able to add detailed product information in a database in later stage and sell this product information in accordance to the surplus value it comports to the recycler [34].

\section{CASE STUDY OF FLAT SCREEN TELEVISION}

\subsection{Differences in LCD LED, LCD CCFL and PDP}

Three Philips FTVs with different and commonly used flat screen technologies are analyzed and compared within this case study. The technology adopted in the first FTV is a Plasma Display Panel (PDP), the second FTV uses a Liquid Cristal Display (LCD) with a backlight consisting of Cold Cathode Fluorescent Lamps (CCFL) and the third is a LCD FTV with backlights consisting of Light
Emitting Diodes (LEDs), which are located at the side of the television.

The current market is expected to reach about 150 million TV sets in 2010 in Europe [2]. The European market is mainly dominated by LCD televisions (>90\%) and there is an ongoing change from CCFL (44\%) to LED (56\%) back lights [35]. PDP televisions are also analyzed within this case study, since they are expected to represent a significant share of EoL FTVs in the coming years, as PDP televisions were mainly sold before 2005 [2].

As shown in Table 1, the material content strongly depends on the adopted FTV technology. PDP FTVs are significantly heavier and have a significantly higher amount of PCBs and floated glass. On the other hand, LCD FTVs contain more plastics, since plastics are, besides the housing, also used in these FTVs to diffuse and polarize the light of the CCFL or LED backlights. From a recycling point of view, an important difference between LCD FTVs with CCFL and LED backlights is that CCFLs contain mercury. Therefore, when these backlight lamps are broken an additional process for the removal of toxic mercury vapors is required. The in this study analyzed, Phillips LCD television with LED backlights is the winner of the Green Awards 2011 and, according to the EISA Green Award jury, for the first time a truly Ecodesign product [36]. This television is perceived as an Ecodesign product due to its innovative reduction in energy consumption, improvement in product architecture and more efficient packaging. This FTV is significantly lighter and has, besides the difference in backlight, an unconventional material composition. The major difference with common LCD FTVs is that mainly aluminum is used in the product housing and structure.

\subsection{Material values and separation efficiencies}

In the case study presented in this paper, the potential revenues of recovered materials and the potential recycling rate in accordance with the European WEEE directive are calculated for two EoL treatment strategies, as shown in Table 1. A comparison is made between an EoL strategy where the FTVs are directly shredded and an EoL treatment strategy where all fasteners in the FTVs are assumed to be reversible by AD.

The material recovery rates for the ferrous metals and the aluminum, used in the calculations, are based on the estimated efficiency of magnetic and eddy current separation processes for shredded material from FTVs [12]. For the direct shredder strategy no polymer recycling is assumed, since all the housing plastics of the analyzed FTVs contain phosphor based Flame Retardants (FR) and plastics with FR are rarely recycled [5]. Nevertheless all polymers with phosphor FR are authorized for re-use by European legislation [3]. The reason why these polymers are often not recycled is that they risk to be polluted in the shredding process with polymers with banned brominated FR and that further separation of these polymers from shredded residue based on their flame retardants is 
Table 1: Value of recovered materials and recycling rates according to the WEEE directive for Philips PDP, LCD with CCFL and LCD with LED FTVs for a direct shredder EoL treatment strategy and an EoL treatment strategy with AD

\begin{tabular}{|c|c|c|c|c|c|c|}
\hline \multirow[b]{2}{*}{ Material Custom Name } & \multicolumn{3}{|c|}{ Weight / TV } & \multirow{2}{*}{$\begin{array}{l}\text { Value of } \\
\text { recovered } \\
\text { material }\end{array}$} & \multirow{2}{*}{$\begin{array}{c}\text { Direct } \\
\text { shedder } \\
\text { strategy }\end{array}$} & \multirow{2}{*}{$\begin{array}{c}A D \\
\text { strategy }\end{array}$} \\
\hline & PDP & $\begin{array}{c}\mathrm{LCD}+ \\
\mathrm{CCFL}\end{array}$ & $\begin{array}{c}\mathrm{LCD}+ \\
\text { LED }\end{array}$ & & & \\
\hline & $(\%)$ & $(\%)$ & $(\%)$ & $(€)$ & $(\%)$ & $(\%)$ \\
\hline PCBs & $14 \%$ & $6 \%$ & $5 \%$ & 900 & $0 \%$ & $95 \%$ \\
\hline Cables & $1 \%$ & $1 \%$ & - & 700 & $0 \%$ & $100 \%$ \\
\hline Plastics (total \% and \% send to incineration) & $11 \%$ & $34 \%$ & $24 \%$ & -160 & $100 \%$ & $1-15 \%$ \\
\hline Thermoplastics & $2 \%$ & $1 \%$ & - & 400 & $0 \%$ & $0 \%$ \\
\hline PET & - & $4 \%$ & $6 \%$ & 660 & $0 \%$ & $100 \%$ \\
\hline PMMA & - & $4 \%$ & $15 \%$ & 2920 & $0 \%$ & $100 \%$ \\
\hline$A B S+P C+F R 40$ & $8 \%$ & $16 \%$ & $1 \%$ & 1370 & $0 \%$ & $100 \%$ \\
\hline$P C+F R 40$ & - & $7 \%$ & - & 1370 & $0 \%$ & $100 \%$ \\
\hline $\mathrm{PC}+\mathrm{GF} 10$ & $1 \%$ & $2 \%$ & $1 \%$ & 300 & $0 \%$ & $100 \%$ \\
\hline Glass & $37 \%$ & - & - & -55 & $0 \%$ & $100 \%$ \\
\hline Glass LCD & - & $9 \%$ & $12 \%$ & 50 & $0 \%$ & $100 \%$ \\
\hline Metals: Ferro based & $26 \%$ & $47 \%$ & $5 \%$ & 220 & $75 \%$ & $100 \%$ \\
\hline Metals: Aluminum based & $11 \%$ & $3 \%$ & $54 \%$ & 2060 & $88 \%$ & $100 \%$ \\
\hline Value of recovered materials / Tonne of televisions $(€)$ & 296 & 57 & 505 & & & \\
\hline Recycling rate according to the WEEE directive & $30 \%$ & $38 \%$ & $51 \%$ & & & \\
\hline Value of recovered materials / Tonne of televisions $(€)$ & 862 & 694 & 914 & & & \\
\hline Recycling rate according to the WEEE directive & $98 \%$ & $92 \%$ & $95 \%$ & & & \\
\hline
\end{tabular}

currently not feasible at high material throughputs [5]. Also, Polymethylmethacrylate (PMMA), Polyethylene Terephtalate (PET) and all PCBs are assumed to be sent to incineration, since the (optical) separation of these materials is not yet proven to be economically viable. For the AD strategy the recovery rates are calculated assuming that all large components are disassembled and separated based on detailed product information. Furthermore, the same separation efficiency is used for the PCBs as presented by Meskers et al. for the manual disassembly of PCBs from Personal Computers [37].

All values of recovered materials used for this case study are based on estimates from prior studies. The values of some recovered materials differ significantly between sources, since they are generally incinerated with energy recovery and not recycled [2, 12, 13, 38]. For this case study, rather optimistic values of recovered materials in Europe, as proposed by Huisman et al., are used [2]. However, to receive these values for recovered material a steady supply of polymers with an assured quality should be achieved. For plastics sent to incineration with energy recovery a cost of 160 euro per tonne is taken into account and for the recovered cables a value of 700 euro per tonne is used, based on data from Salhofer et al. [38]. Both for the LCD, which contains mainly glass, and for the glass of the plasma television the values of the recovered materials are based on data from Cryan et al. [12]. The values of the PCBs are based on the average material content of FTVs, as described by Huisman et al. [2], and values of recovered PCBs, as used by Keller [2, 39].

\subsection{Conventional EoL treatment versus AD}

The case study shows that for an EoL treatment strategy with direct shredding and commonly used separation processes, such as magnetic separation and eddy current separation, a considerable value can be recovered from PDP FTVs, since these TVs contain a high percentage of aluminum and ferrous metals. However, from LCD FTVs with CCFLs only a low value can be recovered. Nonetheless, an additional process for the removal of toxic mercury vapors is only required for these FTVs with CCFLs. For the LCD FTV with LED backlights a considerably higher value can be recovered compared to the other FTVs analyzed in this case study. The main reason here for, is the exceptionally high amount of aluminum that this Ecodesign product contains, which can easily be recovered with a direct shredder strategy. Therefore, this LCD FTV with LED can be described as a product which is successfully designed to improve the amount of materials which can be recovered with a conventional EoL treatment with direct shredding.

When comparing both EoL treatment strategies, there is a clear improvement in value of recovered materials possible by implementing an EoL treatment strategy with AD. Mostly for the LCD FTV with CCFL a significant improvement in the value of recovered materials of about 600 euro per ton can be achieved, since an EoL treatment strategy with $\mathrm{AD}$ allows to recycle most plastics and PCBs. Accordingly, these calculations also determine that, neglecting the time value of money, about 18 euro per LCD FTV with CCFL is the total maximum investment for the implementation of active fasteners and additional 
process in the EoL treatment, which can make AD an economically preferable EoL treatment strategy.

The recycling rates calculated for the direct shredding strategy for the in this case study analyzed LCD FTVs are below the quotas required by the current European WEEE directive. Consequently, improvements in the recycling rate will be required when the volume of EoL LCD FTVs increases. However, the recycling rate is calculated for a combined treatment of consumer products, of which FTVs currently constitute only a small share. Based on these results, it can be expected that recycling plastics glass will be compulsory to achieve the recycling rates of the upcoming recast of the WEEE directive. A significant increase in the percentage of recycled materials can be achieved by implementing an EoL treatment strategy with $\mathrm{AD}$, as demonstrates by the case study. However, to permit recycling of all materials from different components after active disassembling a product, detailed product information, such as the used type of flame retardant, is required. If all this information is available the EoL, active disassembly has the potential to shift an EoL treatment with systematic disassembly from a cost factor to a profit generating activity.

\section{CONCLUSION}

Based on the presented case study it can be concluded that, compared to the conventional EoL treatment with direct product shredding, there is a high increase in recycling rate and value of recovered materials possible by implementing active fasteners in flat screen televisions. However, further developments in the field of $\mathrm{AD}$ are essential to make the implementation of active fasteners technically feasible for the current generation of flat screen televisions and to overcome the economic and ecologic constraints mentioned in this paper. Furthermore, detailed product information is required for an EoL treatment with $\mathrm{AD}$ to allow the identification of the required trigger for $\mathrm{AD}$ and an accurate sorting of disassembled components for further treatment. To facilitate the product identification at the EoL robust technologies, such as Radio Frequency Identification, should be implemented in products with active fasteners.

\section{ACKNOWLEDGEMENTS}

The authors gratefully acknowledge the financial support from the Institute for the Promotion of Innovation by Science and Technology in Flanders (IWT) for the EXTRACT DIRECT project, within which this research is performed. The authors also like to acknowledge Philips as a partner in this project.

\section{REFERENCES}

[1] K. Loannou, Managing Sustainability in Product Design and Manufacturing, Glocalized Solutions for Sustainability in Manufacturing, 2011.
[2] J. Huisman, et al., "2008 Review of Directive 2002/96 on Waste Electrical and Electronic Equipment (WEEE)," United Nations University2007 2008.

[3] European-Parliament, "Directive 2002/96/EC of the European Parliament and of the Council of 27 January 2003 on Waste Electrical and Electronic Equipment (WEEE)," ed, 2003, p. 24.

[4] Council-of-the-European-Union, "2008/0241 (COD) Proposal for a Directive of the European Parliament and of the Council on Waste Electrical and Electronic Equipment (WEEE) (Recast)," ed, 2011, p. 104.

[5] M. Schlummer, et al., "Characterisation of polymer fractions from waste electrical and electronic equipment (WEEE) and implications for waste management," Chemosphere, vol. 67, pp. 1866-1876, 2007.

[6] C. Luttropp, Eco Quality Polymers-EQP, Glocalized Solutions for Sustainability in Manufacturing, 2011.

[7] J. R. Duflou, et al., "Efficiency and feasibility of product disassembly: A case-based study," CIRP Annals - Manufacturing Technology, vol. 57, pp. 583-600, 2008.

[8] F. Torres, "Automatic PC disassembly for component recovery," The international journal of advanced manufacturing technology, vol. 23, p. 39, 2004.

[9] B. Basdere, "Disassembly factories for electrical and electronic products to recover resources in product and material cycles," Environmental science \& technology, vol. 37, p. 5354, 2003.

[10] M. Merdan, et al., "Towards ontology-based automated disassembly systems," in IECON 2010 - 36th Annual Conference on IEEE Industrial Electronics Society, 2010, pp. 1392-1397.

[11] H. J. Kim, et al., "Emulation-based control of a disassembly system for LCD monitors," International Journal of Advanced Manufacturing Technology, vol. 40, pp. 383-392, 2009.

[12] J. Cryan, et al., "Demonstration of Flat Panel Display recycling technologies," WRAP2010.

[13] L. E. Mike Bennett, Lidia Goyos-Ball, Robin Hilder, Dr Phillip Hall, Liz Morrish, Roger Morton and Nicola Myles,, "Separation of mixed WEEE plastics," WRAP2009.

[14] T. Harjula, "Design for disassembly and the environment," CIRP annals, vol. 45, p. 109, 1996.

[15] B. Willems, et al., "Design for Active Disassembly (DfAD) - An outline for future research," presented at the IEEE International Symposium on Electronics \& the Environment, 2005.

[16] B. Willems, et al., "Can large-scale disassembly be profitable? A linear programming approach to 
quantifying the turning point to make disassembly economically viable," International Journal of Production Research, vol. 44, pp. 1125-1146, 2006.

[17] J. R. Duflou, et al., "Towards self-disassembling products - Design solutions for economically feasible large-scale disassembly," Innovation in Life Cycle Engineering and Sustainable Development, pp. 87-110, 2006.

[18] J. Carrell, et al., "Review and future of active disassembly," International Journal of Sustainable Engineering, vol. 2, pp. 252-264, 2009.

[19] S. D. Savransky, Engineering of Creativity : Introduction to Triz Methodology of Inventive Problem Solving, 2000.

[20] J. D. Chiodo, et al., "Active Disassembly using Shape Memory Polymers for the mobile phone industry," Proceedings of the 1999 Ieee International Symposium on Electronics and the Environment, Isee - 1999, pp. 151-156, 344, 1999.

[21] J. D. Chiodo, et al., "An initial investigation into active disassembly using shape memory polymers," Proceedings of the Institution of Mechanical Engineers Part B-Journal of Engineering Manufacture, vol. 215, pp. 733-741, 2001.

[22] J. D. Chiodo, et al., "Isolating LCD's at end-oflife using active disassembly technology: A feasibility study," in Proceedings of the 2000 Ieee International Symposium on Electronics and the Environment, 2000, pp. 318-323, 359.

[23] J. D. Chiodo, et al., "Preliminary investigations of active disassembly using shape memory polymers," in First International Symposium on Environmentally Conscious Degign and Inverse Manufacturing, 1999, pp. 590-596, 1021.

[24] J. D. Chiodo, et al., "Shape memory alloy actuators for active disassembly using 'smart' materials of consumer electronic products," Materials \& Design, vol. 23, pp. 471-478, Aug 2002.

[25] D. H. Nick Jones, Habib Hussein, Eric Billett, Joseph Chiodo, "Towards self-disassembling vehicles," The journal of sustainable product design, vol. 3, pp. 59-74, 2003.

[26] N. Jones, et al., "Towards self-disassembling vehicles," The journal of sustainable product design, vol. 3, pp. 59-74, 2003.

[27] T. Doi, et al., "Development of a recyclable PVmodule: trial manufacturing and evaluation," in Photovoltaic Energy Conversion, 2003. Proceedings of 3rd World Conference on, 2003, pp. 1952-1955 Vol.2.

[28] B. Willems, et al., "Pressure-triggered active fasteners: Design results using topology optimization," Proceedings of the 2007 Ieee International Symposium on Electronics \& the Environment, Conference Record, pp. 184-189 262, 2007.

[29] H. Neubert, "Simultan lösbare Verbindungen zur Rationalisierung der Demontage in der Feinwerktechnik," Technical University of Dresden, 2000.

[30] T. Suga and N. Hosoda, "Active disassembly and reversible interconnection," Proceedings of the 2000 Ieee International Symposium on Electronics and the Environment, pp. 330-334 359, 2000.

[31] S. Nakamura and E. Yamasue, "Hybrid LCA of a Design for Disassembly Technology: Active Disassembling Fasteners of Hydrogen Storage Alloys for Home Appliances," Environmental Science \& Technology, vol. 44, pp. 4402-4408, Jun 152010.

[32] A. K. Parlikad, "RFID-based product information in end-of-life decision making," Control engineering practice, vol. 15, p. 1348, 2007.

[33] K. A. Hribernik, Intelligent Products to Support Closed-Loop Reverse Logistics, Glocalized Solutions for Sustainability in Manufacturing, 2011.

[34] P. Vanegas, et al., "Information exchange requirements for cradle to cradle implementation in an industrial setting: EoL treatment of flat screen televisions," presented at the Life Cycle Management, Berlin, 2011.

[35] DisplaySearch. (2010). LCD TVs to Exceed 180 Million Units in 2010. Available: http://www.displaysearch.com

[36] C. Boks, State-of-the-art Ecodesign on the Electronics Shop Shelves? A Quantitative Analysis of Developments in Ecodesign of TV Sets, Glocalized Solutions for Sustainability in Manufacturing, 2011.

[37] C. Meskers, et al., "Impact of pre-processing routes on precious metal recovery from PCs," presented at the EMC 2009, Innsbruck, Austria, 2009.

[38] S. Salhofer, et al., "Recycling of LCD Screens in Europe - State of the Art and Challenges," in Glocalized Solutions for Sustainability in Manufacturing, J. Hesselbach and C. Herrmann, Eds., ed: Springer Berlin Heidelberg, 2011, pp. 454-458.

[39] M. Keller, "Assesment of gold recovery processes in Bangalore, India and evaluation of an alternative recycling path for printed wiring boards: A case study," Institute for Spatial and Landscape Planning, Regional Resource Management, ETH Zurich, 2006. 